\title{
The comparison of solar water heating system operation parameters calculated using traditional method and dynamic simulations
}

\author{
Krzysztof Sornek ${ }^{1, a}$ \\ ${ }^{1}$ AGH University, Faculty of Energy and Fuels, Mickiewicza Av. 30, 30-059 Krakow, Poland
}

\begin{abstract}
The proper design of renewable energy based systems is really important to provide their efficient and safe operation. The aim of this paper is to compare the results obtained during traditional static calculations, with the results of dynamic simulations. For this reason, simulations of solar water heating (SWH) system, designed for a typical residential building, were conducted in the TRNSYS (Transient System Simulation Tool). Carried out calculations allowed to determine the heat generation in the discussed system as well as to estimate the efficiency of considered installation. Obtained results were compared with the results from other available tool based on the static calculations. It may be concluded, that using dynamic simulations at the designing stage of renewable energy based systems may help to avoid many exploitation problems (including low efficiency, overheating etc.) and allows to provide safe exploitation of such installations.
\end{abstract}

\section{Introduction}

The proper sizing of the components of arenewable energy based systems is a complex problem which includes both predictable (performance characteristics of individual elements) and unpredictable (weather data) parameters. Therefore, computer modelling presents many advantages including [1]:

- elimination of the expense of building prototypes,

- understandable organization of the complex systems,

- possibility to optimise the system components,

- possibility to estimate the amount of energy delivery from the system,

- possibility to estimate the design variable changes on system.

From software dedicated to computer modelling of energy systems, TRNSYS (Transient System Simulation Tool) was used to simulate operation of solar water heating (SWH) system designed for a typical residential building.

TRNSYS is worldwide known software allows to dynamic simulation of the energy systems operation. Primarily, it is used to simulate renewable energy based installations, including solar water heating (SWH) systems. From available references we can mention some investigations devoted to modelling and performance evaluation of solar domestic hot water systems [2], investigation of the effect of load profile [3], and simulation of the systems for hot water preparation but using e.g., heat pumps assisted by solar energy [4]. There are also many works devoted to individual elements of the solar water heating systems. For example, Morrison and Braun studied characteristics of horizontal and vertical tanks [5], Shariah and Ecevit studied the effect of different

\footnotetext{
a Corresponding author: krzysztof.sornek@agh.edu.pl
}

load temperatures on the performance of the solar hot water systems with auxiliary electric heaters [6], Shariah et al. optimized the tilt angle of the collectors [7] and Wongsuwan and Kumar studied the performance of forced circulation system [8].

These models aim to simulate the behavior of a solar thermal collector and are usually based on the energy transfer phenomena (such as radiation, convection and conduction) and on the thermophysical properties of materials $[9,10]$. Other models are intended to serve as a basis for developing experimental test methods foridentification of the characteristic parameters of the collector through nonintrusive means $[11,12]$.

The accuracy of TRNSYS simulations is high and close to the performance of solar water heating systems in real conditions. It was demonstrated e.g. in [13], where energy generated in thermal collectors in the TRNSYS simulation was only $1.2 \%$ higher than the measured one. On the other hand, on a seasonal basis the deviations had higher values and opposite trend (up to \pm 7 $8 \%$ of average deviations weighted on the monthly transferred energy). In another case, comparison of the system energy yield, calculated using TRNSYS for periods higher than one month, with measured energy yield for these periods, shows a very good agreement with differences lower than $\pm 3 \%$ [14].

Simulations are considered in general as powerful tool for modelling, design, prediction of performance and research and development of the energy systems. However, as there are limits to their use - a high level of skill and scientific judgement is required in order to produce correct and useful results [15]. 


\section{Methodology}

The initial step in modelling is derivation of a structure to be used to represent the analysed system (it is always an imperfect copy of reality structure and should not be confused with the real system). The first established elements in the developing structures are boundaries conditions consistent with the considered problem. This is accomplished by specifying internal and external items, processes and effects. Simplified analysis methods have such advantages as computational speed, low costs and rapid turnaround. On the other hand, disadvantages include limited flexibility for design optimisation and lack of control over assumptions.

The following sections describe the assumptions of solar water heating system simulations using TRNSYS software and structure of the considered installation.

\subsection{Assumptions of the dynamic simulations}

The TRNSYS allows to simulate operation of the variety types of solar thermal collectors, including e.g. flat-plate and evacuated tube collectors (representing respectively by Type 1 and Type 71). These components model the thermal performance using a quadratic efficiency equation, which is a generalization from the HottelWhillier equation (eq. 1). Thermal performance of the collector array is determined by the number of modules in series and the characteristics of eachmodule [16].

$$
\eta=\frac{Q_{u}}{A \cdot I_{T}}=\frac{\dot{m} \cdot c_{p f} \cdot\left(T_{0}-T_{i}\right)}{A \cdot I_{T}}=F_{R}(\tau \alpha)_{n}-F_{R} \cdot U_{L} \frac{T_{i}-T_{a}}{I_{T}}
$$

where:

$\mathrm{QU}$ - heat generated in collector array, $\mathrm{kJ} / \mathrm{h}$

A - total collector array aperture or gross area, $\mathrm{m}^{2}$

$\mathrm{I}_{\mathrm{T}}$ - global radiation incident on the solar collector, $\mathrm{kJ} /\left(\mathrm{h} \cdot \mathrm{m}^{2}\right)$

$\mathrm{m}$ - flowrate at use conditions, $\mathrm{kg} / \mathrm{h}$

$\mathrm{c}_{\mathrm{pf}}$ - specific heat of collector fluid, $\mathrm{kJ} /(\mathrm{kg} \cdot \mathrm{K})$

$\mathrm{T}_{\mathrm{i}}$ - inlet temperature of fluid to collector, ${ }^{\circ} \mathrm{C}$

$\mathrm{T}_{\mathrm{o}}$ - outlet temperature of fluid from collector, ${ }^{\circ} \mathrm{C}$

$\mathrm{T}_{\mathrm{a}}$ - ambient (air) temperature, ${ }^{\circ} \mathrm{C}$

$F_{R}$ - overall collector heat removal efficiency factor, -

$\tau$ - short-wave transmittance of the collector cover(s), -

$\alpha$ - short-wave absorptance of the absorber plate, -

$\tau \alpha_{\mathrm{n}}-(\tau \alpha)$ at normal incidence, -

$\mathrm{U}_{\mathrm{L}}$ - overall thermal loss coefficient of the collector per unit area, $\mathrm{kJ} /\left(\mathrm{h} \cdot \mathrm{m}^{2} \cdot \mathrm{K}\right)$

The loss coefficient $U_{L}$ is not exactly constant. Taking into account a linear dependency of $U_{L}$ versus $\left(T_{i}-T_{a}\right)$, the thermal performance may be expressed as:

$$
\eta=\frac{Q_{u}}{A \cdot I_{T}}=F_{R}(\tau \alpha)_{n}-F_{R} \cdot U_{L} \frac{T_{i}-T_{a}}{I_{T}}-F_{R} \cdot U_{L / T} \frac{\left(T_{i}-T_{a}\right)^{2}}{I_{T}}
$$

where:

$\mathrm{U}_{\mathrm{L} / \mathrm{T}}$ - thermal loss coefficient dependency on $\mathrm{T}$, $\mathrm{kJ} /\left(\mathrm{h} \cdot \mathrm{m}^{2} \cdot \mathrm{K}^{2}\right)$
Equation (2) can be rewritten as:

$$
\eta=a_{0}-a_{1} \frac{T_{i}-T_{a}}{I_{T}}-a_{2} \frac{\left(T_{i}-T_{a}\right)^{2}}{I_{T}}
$$

where:

$\mathrm{a}_{0}$ - intercept (maximum) of the collector efficiency, -

$a_{1}$ - negative of the first-order coefficient in collector efficiency equation, $\mathrm{kJ} /\left(\mathrm{h} \cdot \mathrm{m}^{2} \cdot \mathrm{K}\right)$

$\mathrm{a}_{2}$ - negative of the second-order coefficient in collector efficiency equation, $\mathrm{kJ} /\left(\mathrm{h} \cdot \mathrm{m}^{2} \cdot \mathrm{K}^{2}\right)$

The thermal efficiency is defined by three parameters defined as: $a_{0}, a_{1}$ and $a_{2}$. Those parameters are available for collectors tested according to ASHRAE (American Society of Heating, Refrigerating, and Air-Conditioning Engineers) standards and rated by SRCC (Solar Rating and Certification Corporation), as well as for collectors tested according to the another European Standards.

\subsection{Structure of the solar water heating system}

Considered solar water heating system has a typical configuration dedicated for single-family houses $[17,18]$ and including flat-plate solar thermal collectors, water tank, circulating pump, diverter, tee piece, controller and other components.

The general assumptions of considered system are:

- location: Warsaw (Poland),

- daily hot water consumption: $60 \mathrm{dm}^{3}$ per person,

- number of residents: 5 ,

- solar fraction achieved (the ratio of solar heat yield to the total energy requirement for water heating): $60 \%$,

- hot water temperature: $55^{\circ} \mathrm{C}$,

- cold water temperature: $10^{\circ} \mathrm{C}$,

- collectors' orientation: $0^{\circ}$ (south),

- collectors' inclination: $35^{\circ}$,

- type of collectors: flat-plate,

- distance between the tank inlet and collectors: $10 \mathrm{~m}$. Calculations have been conducted using traditional method for designing SHW systems. The average global insolation for the Warsaw was taken as $1050 \mathrm{kWh} / \mathrm{m}^{2}$ per year and time step was set as one month. The calculated number of connected in series solar thermal collectors (with parameters shown in Tab. 1) is five.

Table 1. The basic parameters of chosen solar thermal collectors.

\begin{tabular}{|l|c|}
\hline \multicolumn{1}{|c|}{ Collector's parameter } & Value, unit \\
\hline Aperture area & $1.85 \mathrm{~m}^{2}$ \\
\hline Optical efficiency & 0.791 \\
\hline $1^{\text {st }}$ order heat loss coefficient & $3.782 \mathrm{~W} /\left(\mathrm{m}^{2} \mathrm{~K}\right)$ \\
\hline $2^{\text {nd }}$ order heat loss coefficient & $0.015 \mathrm{~W} /\left(\mathrm{m}^{2} \mathrm{~K}^{2}\right)$ \\
\hline Power output (when $\left.\mathrm{T}_{\mathrm{m}}-\mathrm{T}_{\mathrm{a}}=0 \mathrm{~K}\right)$ & $1.46 \mathrm{~kW}^{*}$ \\
\hline Power output (when $\left.\mathrm{T}_{\mathrm{m}}-\mathrm{T}_{\mathrm{a}}=30 \mathrm{~K}\right)$ & $1.23 \mathrm{~kW}^{*}$ \\
\hline Power output $\left(\right.$ when $\left.\mathrm{T}_{\mathrm{m}}-\mathrm{T}_{\mathrm{a}}=50 \mathrm{~K}\right)$ & $1.05 \mathrm{~kW}^{*}$ \\
\hline *) tested according to $\mathrm{EN} 12975-2, \quad$ assuming irradiance \\
$\mathrm{G}=1000 \mathrm{~W} / \mathrm{m}^{2}$ and flow rate $0.02 \mathrm{~kg} / \mathrm{s}$ per m²
\end{tabular}


The structure of the solar water heating system has been implemented into TRNSYS program (see Fig. 2). The load profile, based on predicted usage of hot water in residential buildings, was added. The weather data for the Warsaw has been taken from Meteonorm database. Time step for simulation was set to 15 minutes.

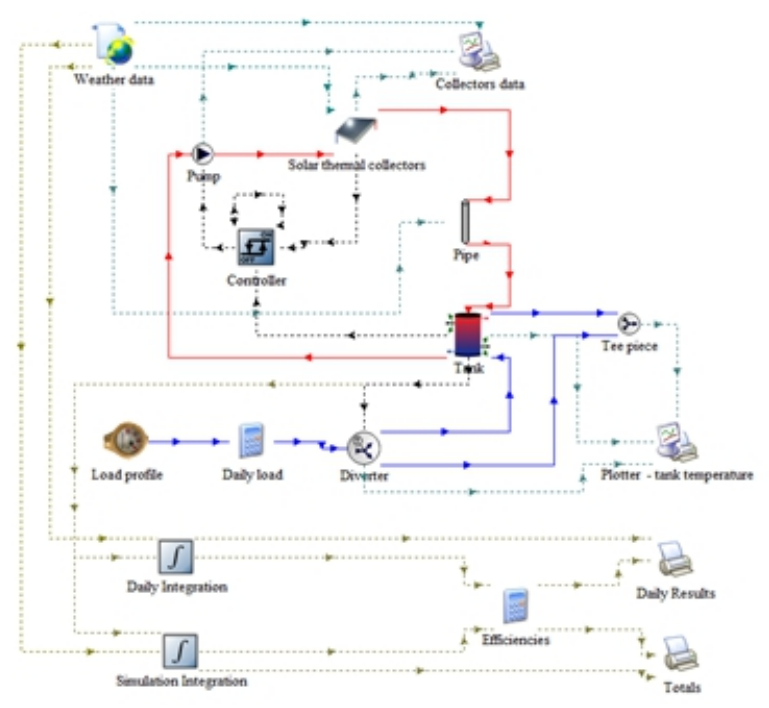

Figure 2. The structure of solar hot water system implemented in TRNSYS program.

\section{Discussion of the results}

The results obtained during traditional calculations (using one of the available tools) were compared with the results of dynamic simulations (conducted in TRNSYS).

\subsection{Results from traditional calculations}

The average yearly ratio of solar heat yield to the total energy requirement for hot water heating calculated based on the above listed assumptions, is $63.4 \%$. On the other hand, monthly values of the solar fraction achieving varies from $9 \%$ in December to $117 \%$ in May. There are also high in June, July and August (equal and higher than 100\%) as well as exceed the average yearly value still in April and September. The variations in solar fraction achieving during year for considered solar water heating installation is shown in. Fig. 4.

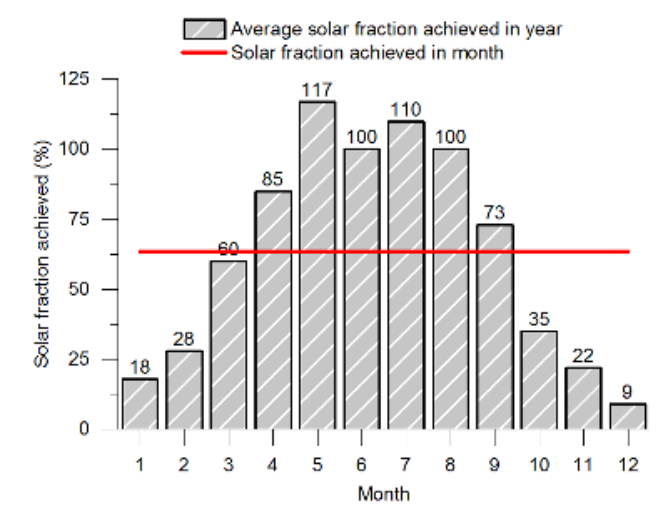

Figure 4. Solar fraction achieved in month calculated using traditional method

\subsection{Results from dynamic simulations}

Comparing solar fraction achieved (SFA) calculated using traditional method with results of dynamic simulations, we can see significant differences. The amount of heat generated in collectors is lower than expected for about $90 \%$ of time in the year and consequently the value of solar fraction achieved is close to $40 \%$. What is also important, the SFA values strongly fluctuate in time (see Fig. 5).

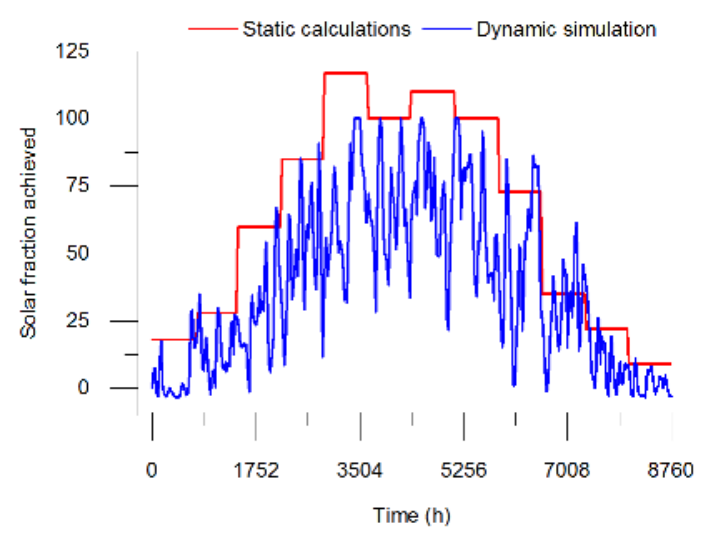

Figure 5. The comparison of solar fraction achieved calculated using traditional method and using dynamic simulations.

Taking into account high accuracy of simulations done in TRNSYS, it can be estimated the amount of additional energy delivered by auxiliary heater (e.g. electric heater) to meet the energy demands of SWH system (see. Fig. 6).

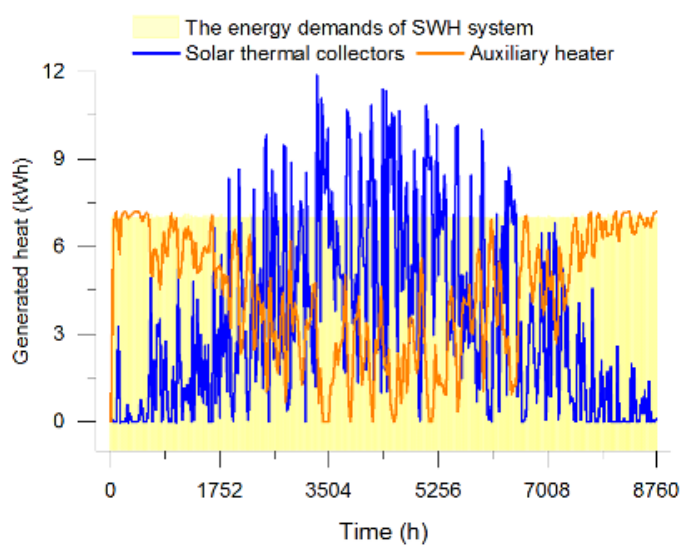

Figure 6. The amount of heat generated in solar thermal collectors and auxiliary heater.

As we can notice in Fig. 6, the total amount of energy generated in collectors and taken from the network in the whole year is respectively $1238 \mathrm{kWh}$ and $1585 \mathrm{kWh}$ (for assumed energy demands of solar water heating system). These values can be directly used to calculate the cost of electricity consumption for heating water. As we can conclude from dynamic simulations, real cost of auxiliary heater operation is significantly higher than expected basis on the conducted static calculations.

The real amount of heat generated in collectors may be different from the value calculated during carried out simulations. On the other hand, basis on the investigations available in literature, it can be expected, that average 
difference should be no more than 5\%. Field tests (for validation calculated data) are planning as a next step of described research.

\section{Conclusions}

The analysis of results from traditional calculations and dynamic simulations shows significant differences in the amount of heat generated in solar thermal collectors. The solar fraction achieved during TRNSYS simulations fluctuates in time and its average yearly value is close to $40 \%$ (while SFA calculated using traditional method exceeds $60 \%$ ). This difference makes, that more energy must be taken from network to power an auxiliary heater ( $\sim 1585 \mathrm{kWh}$ in comparison to $\sim 1238 \mathrm{kWh}$, calculated using traditional methods). Consequently, the estimated costs of water heating are higher than expected.

Due to high accuracy, the use of dynamic simulations in the stage of designing solar water heating systems may help to avoid many further exploitation problems (such as low efficiency, overheating etc.). It may also help to provide safe exploitation of SWH installations.

The work has been completed as part of the statutory activities of the Faculty of Energy and Fuels at the AGH University "Studies concerning the conditions of sustainable energy development". It was realized using infrastructure of the Center of Energy, AGH University. Supervisor: prof. Mariusz Filipowicz

\section{References}

1. S.A. Kalogirou, C. Papamarcou, Renew Energ 21, 471-493 (2000)

2. M. Oishi, T. Noguchi, Eurosun'2000 (2000)

3. U. Jordan, K. Vajen, Eurosun'2000 (2000)

4. B. Mette, H. Druck, S. Bachmann, H. MullerSteinhagen, ISES Solar World Congress (2009)

5. G.L. Morrison, J.E. Braun, Sol Energy 34, 389-405 (1985)

6. A. Shariah, A. Ecevit, Energ Convers Menage 36, 289-296 (1995)

7. A. Shariah, M.A. Al-Akhra, I.A. Al-Omari, Renew Energ 26, 587-598 (2002)

8. W. Wongsuwan, S. Kumar, Int J Sustain Energ 24,6986 (2005)

9. J. Cadafalch, Sol Energy 83, 2157-2164 (2009)

10. M.C. Rodriguez-Hidalgo, P.A. Rodriguez-Aumente, A. Lecuona, G.L. Gutierrez-Urueta, R. Ventas, Appl Therm Eng 31, 2394-2404 (2011)

11. S. Fischer, H. Muller-Steinhagen, ISES World Congress 2007 (2009)

12. W. Kong, Z. Wang, J. Fan, P. Bacher, B. Perers, Z. Chen, S. Furbo, Energy 86, 1838-1848 (2012)

13. F. Bava, S. Furbo, B. Perers, Energy Procedia 70, 412 (2015)

14. P. Almeida, M.J. Carvalho, R. Amorim, J.F. Mendes, V. Lopes, Sol Energy 104, 60-70 (2014)

15. S.A. Kalogirou, Prog Energ Combust 30, 231-295 (2004)
16. W. DeSoto, S.A. Klein, W.A. Beckman, Sol Energy J (2005)

17. K. Sornek, K. Rzepka, T. Mirowski, Rynek Instalacyjny 3, 47-52 (2015)

18. T. Mirowski, K. Sornek, Polityka Energetyczna 18, 73-84 (2015) 